\title{
A synthetic molecular pentafoil knot
}

\author{
Jean-François Ayme1, Jonathon E. Beves', David A. Leigh, Roy T. McBurney', Kari Rissanen² \\ and David Schultz'
}

\begin{abstract}
Knots are being discovered with increasing frequency in both biological and synthetic macromolecules and have been fundamental topological targets for chemical synthesis for the past two decades. Here, we report on the synthesis of the most complex non-DNA molecular knot prepared to date: the self-assembly of five bis-aldehyde and five bis-amine building blocks about five metal cations and one chloride anion to form a 160-atom-loop molecular pentafoil knot (five crossing points). The structure and topology of the knot is established by NMR spectroscopy, mass spectrometry and $\mathrm{X}$-ray crystallography, revealing a symmetrical closed-loop double helicate with the chloride anion held at the centre of the pentafoil knot by ten $\mathrm{CH}$... $\mathrm{Cl}^{-}$hydrogen bonds. The one-pot self-assembly reaction features an exceptional number of different design elements-some well precedented and others less well known within the context of directing the formation of (supra)molecular species. We anticipate that the strategies and tactics used here can be applied to the rational synthesis of other higher-order interlocked molecular architectures.
\end{abstract}

K nots are important structural features in $\mathrm{DNA}^{1}$, are found in some proteins ${ }^{2-5}$ and are thought to play a significant role in the physical properties of both natural and synthetic polymers ${ }^{6,7}$. Although billions of prime knots are known to mathemat$\mathrm{ics}^{8}$, to date the only ones to have succumbed to chemical synthesis using building blocks other than DNA are the topologically trivial unknot (that is, a simple closed loop without any crossing points) and the next simplest knot (featuring three crossing points), the trefoil knot $^{9,10}$. A pentafoil knot-also known as a cinquefoil knot or Solomon's seal knot (the $5_{1}$ knot in Alexander-Briggs notation ${ }^{11}$ ) - is a torus knot $^{12}$ with five crossing points, is inherently chiral, and is the fourth prime knot (following the unknot, trefoil knot and figure-of-eight knot) in terms of number of crossing points and complexity $\mathrm{y}^{8,11,12}$.

Sauvage reported the first molecular knot synthesis ${ }^{13}$, using a linear metal helicate ${ }^{14}$ to generate the three crossing points required for a trefoil knot. Although other syntheses of trefoil knots have been reported ${ }^{15-22}$ (as have composites of trefoil knots ${ }^{23}$ and other molecular topologies such as catenanes ${ }^{24-28}$ and Borromean links ${ }^{29}$ ), higher-order molecular knots remain elusive. Here, we report on the synthesis of a molecular pentafoil knot that combines the use of metal helicates to create crossover points ${ }^{30}$, anion template assembly to form a cyclic array of the correct size $e^{31-33}$, and the joining of the metal complexes by reversible imine bond formation ${ }^{34-37}$ aided by the gauche effect ${ }^{38}$ to make the continuous 160 -atom-long covalent backbone of the most complex non-DNA molecular knot prepared to date.

So far, attempts to make molecular knots with more than three crossing points by extending the linear helicate strategy of Sauvage to ligands with more coordination sites have proved unsuccessful $^{30}$, probably because joining the ends of each strand with the required connectivity becomes increasingly difficult as helicate length increases. An alternative way to use helicates (which generate the necessary crossing points) to make higher-order topologies could be to use cyclic structures or grids, where there is no requirement for there to be long distances between the ends of the strands that are to be connected. To generate the five crossing points required for a pentafoil knot, we modified a motif for generating cyclic metal helicates discovered by Lehn in the mid-1990s ${ }^{31-33}$. Lehn found that double-stranded circular helicates of various sizes could be obtained using $\mathrm{Fe}(\mathrm{II})$ or $\mathrm{Ni}$ (II) ions with tris(bipyridine) ligands with very short inter-bipyridine spacers that destabilized the normally preferred three-metal-ion linear triple helicate. The presence of chloride ions in the reaction mixture led to the selective formation of the five-metal-ion cyclic double helicate. To have the potential to covalently connect the organic ligands to form a knot, we envisioned replacing two of the three bipyridine groups in Lehn's original building blocks with formylpyridine groups, then use their reversible reaction with amines to form imines and generate tris(bidentate) ligand strands. A decade ago we introduced reversible metal-imine bond coordination as an effective means of assembling mechanically interlocked molecules under thermodynamic control ${ }^{34,35}$. This provides a mechanism for correcting 'mistakes' in connectivity that occur during the covalent-capture step of mechanical bond formation and has been widely adopted for this purpose ever since ${ }^{10,29,36,37}$.

The reaction conditions (ethylene glycol, $170{ }^{\circ} \mathrm{C}$ ) ${ }^{31-33}$ used to form cyclic helicates with tris(bipyridine) ligands are not compatible with imine bond formation. Because the product distribution between cyclic double helicate, linear triple helicate and polymer is a delicate thermodynamic balance that could change significantly depending on the structure of the building blocks, reaction conditions, solvent and the nature and stoichiometry of the metal and anions, we first investigated whether it was possible to translate the self-assembly chemistry of the tris(bipyridine) ligands to an imine system.

\section{Results and discussion}

Treatment of bis-aldehyde $\mathbf{1}$ with 1 -aminohexane $\mathbf{2 a}$ in the presence of $\mathrm{FeCl}_{2}$ in $d_{6}$-dimethylsulfoxide $\left(\mathrm{CD}_{3} \mathrm{SOCD}_{3}\right.$, Fig. 1) afforded a purple solution with an initially complex ${ }^{1} \mathrm{H}$ NMR spectrum (see Supplementary Information), indicative of the presence of a range of different monomeric, oligomeric and polymeric species. However, on heating at $60{ }^{\circ} \mathrm{C}$, the ${ }^{1} \mathrm{H}$ NMR spectrum of the reaction mixture gradually simplified until, after $24 \mathrm{~h}$, only a single, highly symmetrical species appeared to be present in solution. The 

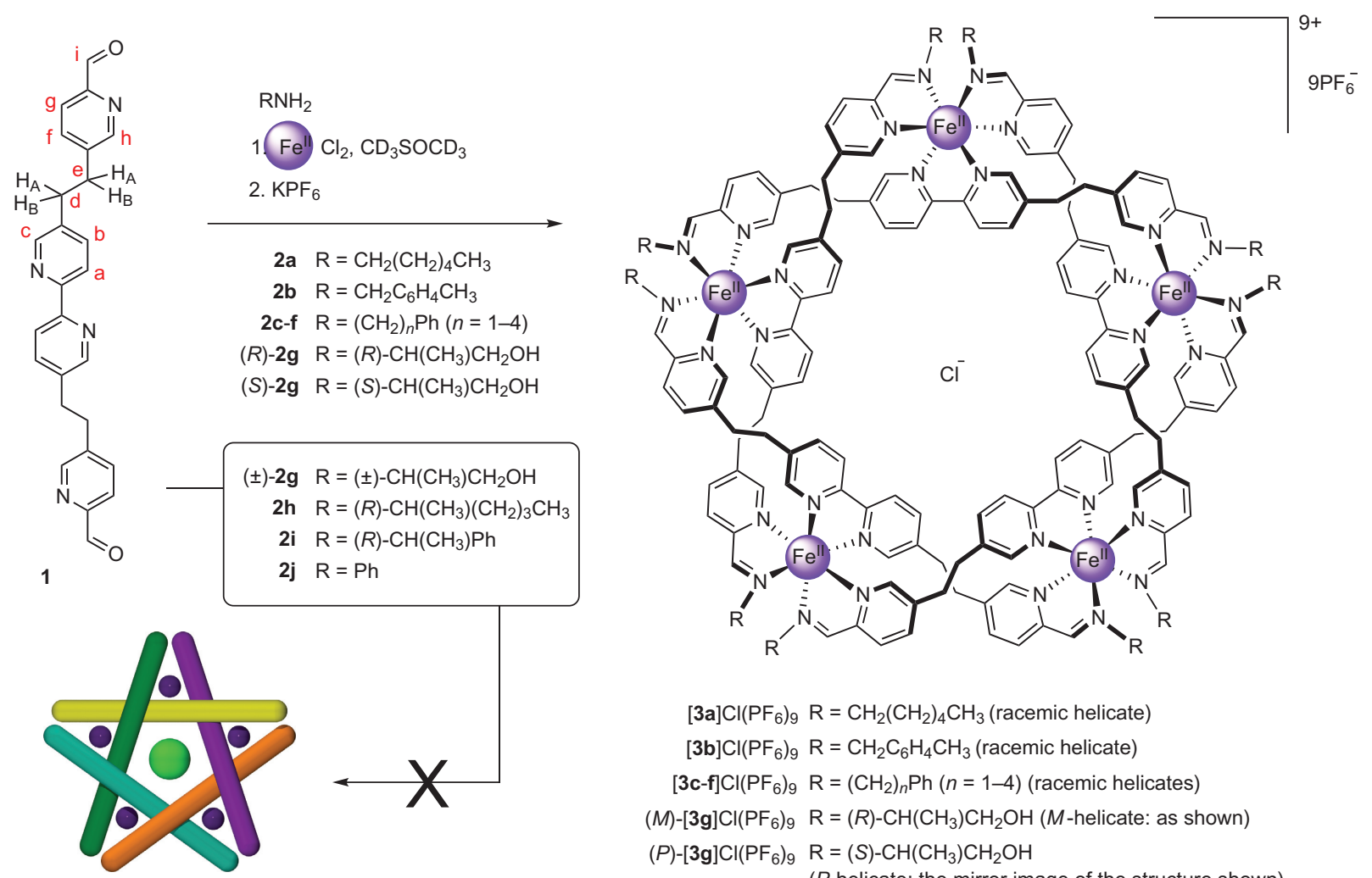

$\begin{array}{rl}{[3 \mathbf{a}] \mathrm{Cl}\left(\mathrm{PF}_{6}\right)_{9} \mathrm{R}} & =\mathrm{CH}_{2}\left(\mathrm{CH}_{2}\right)_{4} \mathrm{CH}_{3} \text { (racemic helicate) } \\ {[3 \mathbf{b}] \mathrm{Cl}\left(\mathrm{PF}_{6}\right)_{9} \mathrm{R}} & =\mathrm{CH}_{2} \mathrm{C}_{6} \mathrm{H}_{4} \mathrm{CH}_{3}(\text { racemic helicate }) \\ {[3 \mathbf{c}-\mathrm{f}] \mathrm{Cl}\left(\mathrm{PF}_{6}\right)_{9} \mathrm{R}} & =\left(\mathrm{CH}_{2}\right)_{n} \mathrm{Ph}(n=1-4)(\text { racemic helicates }) \\ (M)-[3 \mathbf{g}] \mathrm{Cl}\left(\mathrm{PF}_{6}\right)_{9} & \mathrm{R}=(R)-\mathrm{CH}\left(\mathrm{CH}_{3}\right) \mathrm{CH}_{2} \mathrm{OH}(M \text {-helicate: as shown }) \\ (P)-[3 \mathrm{~g}] \mathrm{Cl}\left(\mathrm{PF}_{6}\right)_{9} & \mathrm{R}=(S)-\mathrm{CH}\left(\mathrm{CH}_{3}\right) \mathrm{CH}_{2} \mathrm{OH} \\ & (P \text {-helicate: the mirror image of the structure shown })\end{array}$

Figure 1 | Chloride-template assembly of pentameric iron(II) cyclic double helicates [3a-g] $\mathrm{Cl}_{(}\left(\mathrm{PF}_{6}\right)_{9}$. Reaction conditions: 1. $d_{6}$-dimethylsulfoxide, $60{ }^{\circ} \mathrm{C}$, $24 \mathrm{~h}\left(48 \mathrm{~h}\right.$ for the formation of $(M)-$ and $\left.(P)-[3 g] C l\left(P F_{6}\right)_{9}\right)$. 2. Excess saturated aqueous $\mathrm{KPF}_{6}$. Yields: $[3 a] C l\left(P F_{6}\right)_{9}(63 \%),[3 \mathbf{b}] \mathrm{Cl}\left(\mathrm{PF}_{6}\right)_{9}(56 \%)$, $[3 \mathrm{c}] \mathrm{Cl}\left(\mathrm{PF}_{6}\right)_{9}(30 \%),[3 \mathrm{~d}] \mathrm{Cl}\left(\mathrm{PF}_{6}\right)_{9}(43 \%),[3 \mathrm{e}] \mathrm{Cl}\left(\mathrm{PF}_{6}\right)_{9}(55 \%),[3 \mathrm{f}] \mathrm{Cl}\left(\mathrm{PF}_{6}\right)_{9}(52 \%),(\mathrm{M})-[3 \mathrm{~g}] \mathrm{Cl}\left(\mathrm{PF}_{6}\right)_{9}(34 \%),(\mathrm{P})-[3 \mathrm{gg}] \mathrm{Cl}(\mathrm{PF})_{9}(34 \%)$. Primary amines $($ for example, $\mathbf{2 a}-\mathbf{f}$ ) are generally well tolerated by the cyclic-helicate-forming reaction, whereas most secondary amines (for example, $\mathbf{2} \mathbf{h}$ and $\mathbf{2} \mathbf{i}$ ) and anilines (for example, $\mathbf{2} \mathbf{j})$ are not. The chiral secondary amine 2-amino-1-propanol $((R)$ - or $(S)-\mathbf{2 g})$ is an interesting exception; not only does it form the cyclic pentameric helicate $\left((M)\right.$ - or $\left.(P)-[3 g] C l\left(P_{6}\right)_{9}\right)$, but it does so diastereoselectively with the handedness of the helix dependent on the chirality of the amine used.

thermodynamically driven change in product distribution can occur at relative low temperature $\left(60{ }^{\circ} \mathrm{C}\right.$ as opposed to the $170{ }^{\circ} \mathrm{C}$ used with tris(bipyridine) ligand strands ${ }^{31-33}$ ) because of the reversible formation of the imine bonds and the relatively labile coordination of the iminopyridine groups, both of which promote dynamic exchange between the various reaction products and intermediates.

After cooling to room temperature, treatment with a saturated aqueous $\mathrm{KPF}_{6}$ solution (to exchange chloride anions for hexafluorophosphates) produced a purple precipitate, which was collected by filtration and isolated in 63\% yield (Fig. 1). Electrospray ionization mass spectrometry (ESI-MS) showed that this material had a molecular mass and isotope pattern consistent with a supramolecular complex comprising five ligand strands, five Fe(II) cations, nine $\mathrm{PF}_{6}{ }^{-}$anions and one chloride anion that had not been substituted for hexafluorophosphate, $[\mathbf{3 a}] \mathrm{Cl}\left(\mathrm{PF}_{6}\right)_{9} \quad$ (see Supplementary Information). The symmetry of the ${ }^{1} \mathrm{H}$ NMR spectrum (Fig. 2c) suggested that the pentameric complex was cyclic and the diastereotopic protons of the $\mathrm{CH}_{2}-$ Ar groups (the two protons of the methylene group experience different environments) confirmed the chiral (racemic) helicate geometry shown for $[3 \mathbf{a}]^{10+}$ in Fig. 1 . The $\mathrm{H}^{\mathrm{a}}$ resonances of the bipyridyl ligand are deshielded by $1.42 \mathrm{ppm}$ compared to $\left[\mathrm{Fe}\left(2,2^{\prime} \text {-bipyridine }\right)_{3}\right]\left(\mathrm{PF}_{6}\right)_{2}$ (ref. 39), suggesting $\mathrm{C}-\mathrm{H}$ hydrogen bonding to an electron-rich atom or ion.

The cyclic-helicate-forming reaction proved to be tolerant to other sterically unhindered primary amines (for example, $\mathbf{2 b}-\mathbf{f}$, Fig. 1). Use of 4-methylbenzylamine (2b) generated the corresponding pentameric helicate $[3 \mathbf{b}] \mathrm{Cl}\left(\mathrm{PF}_{6}\right)_{9}$ in $56 \%$ yield. Differences in the chemical shifts of several protons in the iminopyridyl rings $\left(\mathrm{H}^{\mathrm{f}}, \mathrm{H}^{\mathrm{g}}\right.$ and $\mathrm{H}^{\mathrm{h}}$ ) of $\mathbf{3 a}$ and $\mathbf{3 b}$ (Fig. $2 \mathrm{c}$ and $2 \mathrm{a}$ ) show that changes in the nature of the amine can influence the detailed conformation adopted by the cyclic helicate, presumably through small coordination geometry changes at the iron centres.

Anilines (for example, 2j, Fig. 1) and amines with two substituents on the amine-bearing carbon atom (for example, $\mathbf{2 h}$ and $\mathbf{2} \mathbf{i}$, Fig. 1) were generally not tolerated by the cyclic-helicate-forming reaction. However, each enantiomer of 2-amino-1-propanol (2g) formed the corresponding pentameric cyclic helicate in 34\% yield. In this case, the helicates are formed with complete diastereoselectivity (for circular dichroism spectra see Supplementary Information), with the handedness of the cyclic helicate determined by the enantiomer of the amine used ${ }^{40}$, suggesting that it may ultimately be possible to form topologically chiral single enantiomer knots using this assembly system. The selectivity of the particular handedness of the cyclic helicate appears to be due to favourable $\mathrm{CH}$... O interactions between the $\mathrm{H}^{\mathrm{c}}$ protons (shifted by $0.63 \mathrm{ppm}$ relative to $2 \mathrm{a}$ in the ${ }^{1} \mathrm{H}$ NMR spectrum, Fig $2 \mathrm{~b}$ ) and the hydroxyl group of the chiral amine. Even intrinsically weak interactions such as these can have a major effect on the product distribution of the cyclic-helicate-forming reaction (in this case, one handedness of helix being significantly thermodynamically favoured over the other), because ten such interactions are present per pentameric helicate complex. However, the driving force for helix formation is not sufficiently strong to bring about 'self-sorting' ${ }^{41-43}$ : racemic $\mathbf{2 g}$ forms a mixture of oligomers and polymers rather than the two $(M)$ - and $(P)-[3 \mathbf{g}] \mathrm{Cl}\left(\mathrm{PF}_{6}\right)_{9}$ cyclic helicates (Fig. 1).

Using the reaction conditions established for pentameric cyclic double helicate formation (Fig. 1), we investigated replacing the 


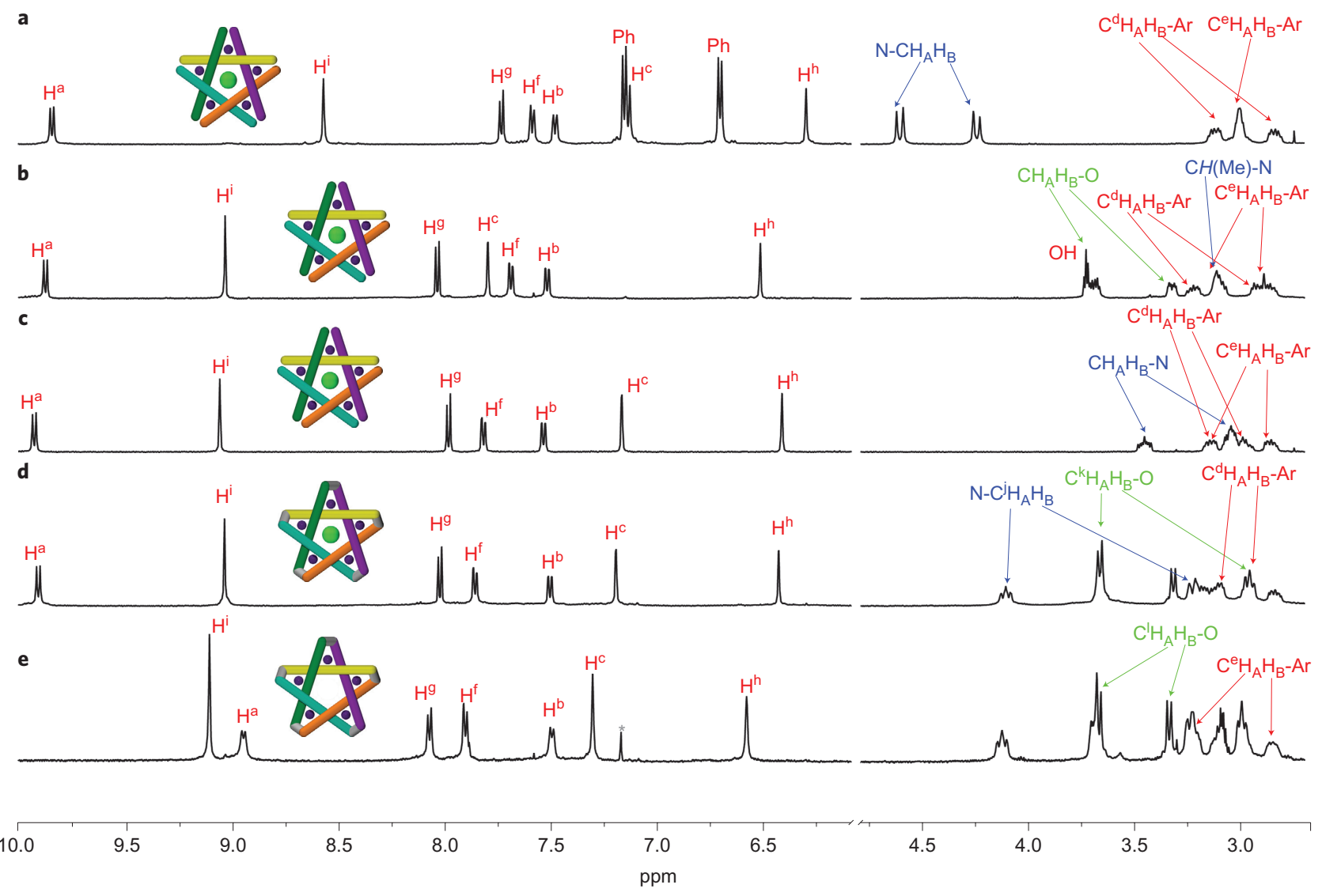

Figure 2 | Partial ${ }^{1} \mathrm{H}$ NMR spectra ( $500 \mathrm{MHz}, \mathrm{CD}_{3} \mathrm{CN}, 298 \mathrm{~K}$ ) of cyclic double helicates and the chloride-complexed and 'empty cavity' pentafoil knot. a, 4-Methylbenzylamine-derived pentameric cyclic helicate $[3 \mathbf{b}] \mathrm{Cl}\left(\mathrm{PF}_{6}\right)_{9} . \mathbf{b},(R)$-2-amino-propanol-derived pentameric cyclic helicate of single handedness $(\mathrm{M})-[3 \mathrm{~g}] \mathrm{Cl}\left(\mathrm{PF}_{6}\right)_{9}$. c, Hexylamine-derived pentameric cyclic helicate $[3 \mathrm{a}] \mathrm{Cl}\left(\mathrm{PF}_{6}\right)_{9}$. d, Pentafoil knot $[6] \mathrm{Cl}\left(\mathrm{PF}_{6}\right)_{9}$. e, 'Empty cavity' pentafoil knot $[6]\left(\mathrm{PF}_{6}\right)_{10}$ in the presence of excess $\mathrm{AgPF}_{6}$. The simplicity of each spectrum is indicative of a symmetrical, cyclic (no endgroups) molecular structure. The $A B$ systems observed for certain resonances (for example, $\mathrm{N}-\mathrm{CH}_{A} \mathrm{H}_{B}$ ) are characteristic of methylene groups in asymmetric environments (as conferred by a helix). The differences between the chemical shifts of $\mathrm{H}^{\mathrm{f}}, \mathrm{H}^{\mathrm{g}}$ and $\mathrm{H}^{\mathrm{h}}$ in some of the helicates probably reflect small changes in geometry at the metal centres with the different ligands. The absence of chloride in the 'empty cavity' pentafoil knot [6] $\left(\mathrm{PF}_{6}\right)_{10}$ is signalled by the large shift in $\mathrm{H}^{\mathrm{a}}$ (e) compared to the other complexes (a-d) in which the $\mathrm{H}^{\mathrm{a}}$ protons are involved in strong $\mathrm{CH}^{\mathrm{N} \cdot \mathrm{Cl}^{-}}$hydrogen bonding. The proton assignments correspond to the lettering shown in Figs 1 and 3.

monoamine starting material with a diamine (Fig. 3). Although simple alkyl chain diamines of various lengths (4) gave complex mixtures of oligomers and polymers under these conditions, the use of diamine 5 led to the formation of a molecular pentafoil knot, $[6] \mathrm{Cl}\left(\mathrm{PF}_{6}\right)_{9}$ (Fig. 3). The ${ }^{1} \mathrm{H}$ NMR spectrum of the reaction mixture took longer to simplify than with most monoamines, but after two days showed the presence of essentially a single low-molecular-weight species (although some polymers are probably also present, consistent with the broad uneven baseline of the ${ }^{1} \mathrm{H}$ NMR spectrum of the crude reaction mixture, see Supplementary Information). After anion exchange and workup, $[6] \mathrm{Cl}\left(\mathrm{PF}_{6}\right)_{9}$ was isolated in $44 \%$ yield. The yield of the knot is very sensitive to the stoichiometry of reactants used, with the best results obtained using a 1:1.1:1.1 ratio of $\mathbf{1}: 5: \mathrm{FeCl}_{2}$. Using strictly equimolar amounts of iron and diamine is particularly important, with even a $10 \%$ excess of amine decreasing the yield of the knot by up to half (see Supplementary Information).

Many of the signals in the ${ }^{1} \mathrm{H}$ NMR spectrum of pristine $[6] \mathrm{Cl}\left(\mathrm{PF}_{6}\right)_{9}$ (Fig. 2d) occur at very similar chemical shifts to the equivalent protons in the hexylamine-derived helicate $3 \mathrm{a}^{10+}$ (Fig. 2c), suggesting that the knot and this helicate are structurally very similar about the iron centres. ESI-MS revealed a series of $m / z$ fragments corresponding to $\left[\left(\mathrm{Fe}_{5} \mathrm{~L}\right) \mathrm{Cl}\right]\left[\mathrm{PF}_{6}\right]_{n}^{(9-n)+}$ (where $\mathrm{L}$ is the organic framework pentafoil knot) for $n=2,3,4,5$ and 6 , indicating that signals are observed for the molecular knot losing between two and six $\mathrm{PF}_{6}{ }^{-}$ions in the mass spectrum (see Supplementary Information).

Single crystals of $[6] \mathrm{Cl}\left(\mathrm{PF}_{6}\right)_{9}$ were obtained by slow diffusion of diethyl ether vapour into a solution of the knot in acetonitrile: toluene (3:2) and the solid-state structure was determined by X-ray crystallography using the Diamond synchrotron source (see Supplementary Information). The crystal structure (Fig. 4) confirms the topology and symmetry of the molecular pentafoil knot. The single organic ligand weaves a continuous path about the five co-planar iron centres, the loop passing over and under itself each time it wraps around a metal ion. At the centre of the structure is the chloride anion, held in place by ten $\mathrm{CH} \cdots \mathrm{Cl}^{-}$hydrogen bonds that are presumably responsible for it not being exchanged during treatment with $\mathrm{KPF}_{6}$ (Fig. 4a). Interestingly, the chloride anion is displaced by $\sim 1.30 \AA$ from the least-squares plane defined by the five $\mathrm{Fe}(\mathrm{II})$ ions (Fig. 4b). Given the symmetry of the ${ }^{1} \mathrm{H}$ NMR spectrum, in solution the chloride anion must oscillate rapidly on the NMR timescale between the different sides of the molecular knot, accompanied by significant conformational changes in the overall framework of the structure.

The conformations of the groups used to link the metal centres suggest why the pentafoil knot is not favoured using simple alkyl chain diamines (Fig. 4a). To connect each metal centre to the 


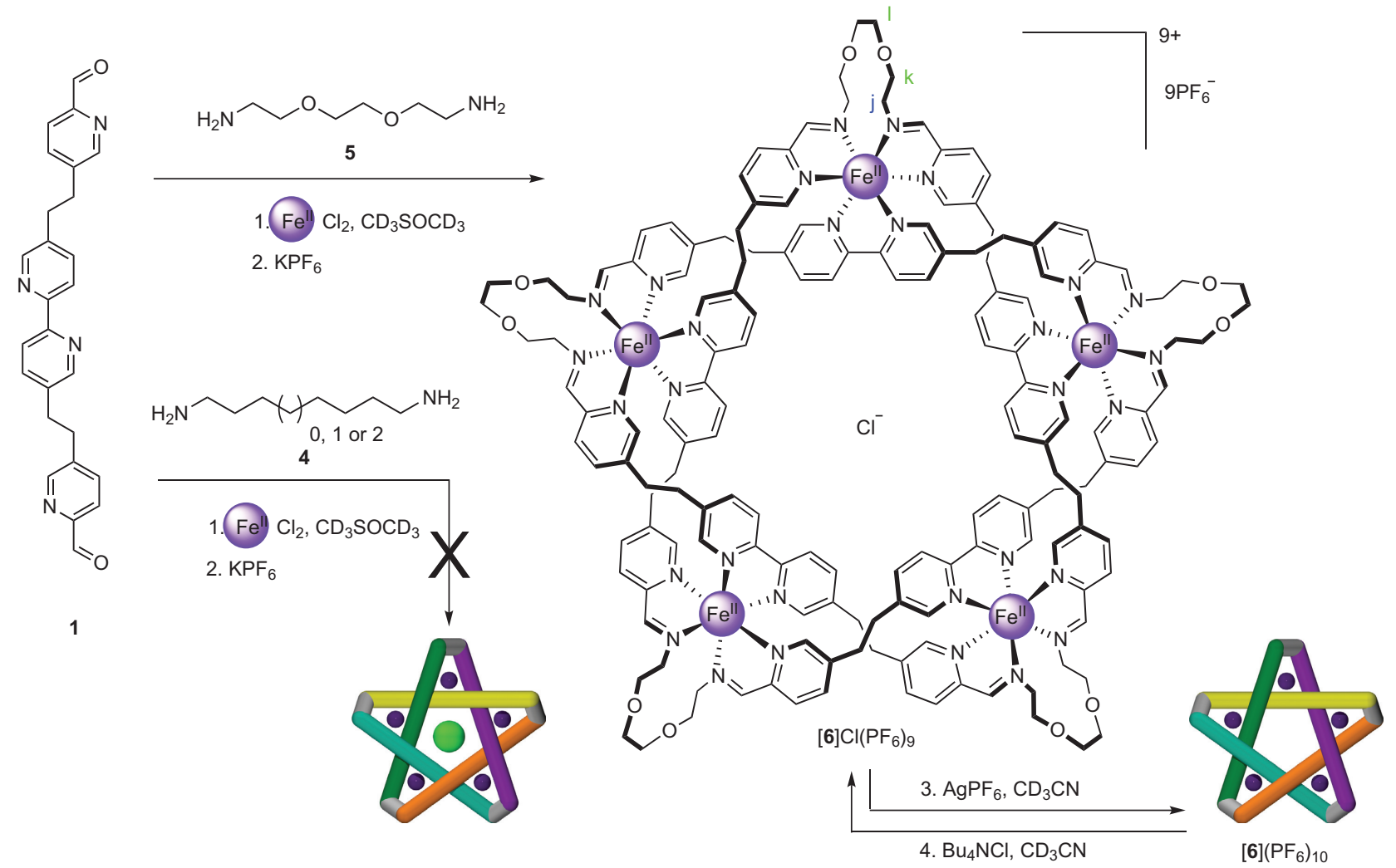

Figure 3 | Synthesis of molecular pentafoil knot $[6] \mathrm{CI}\left(\mathrm{PF}_{6}\right)_{9}$ and 'empty cavity' pentafoil knot [6]( $\left.\mathrm{PF}_{6}\right)_{10}$. Reaction conditions: 1. $d_{6}$-dimethylsulfoxide,

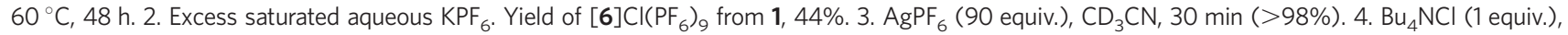
$\mathrm{CD}_{3} \mathrm{CN}, 5 \min (>98 \%)$.
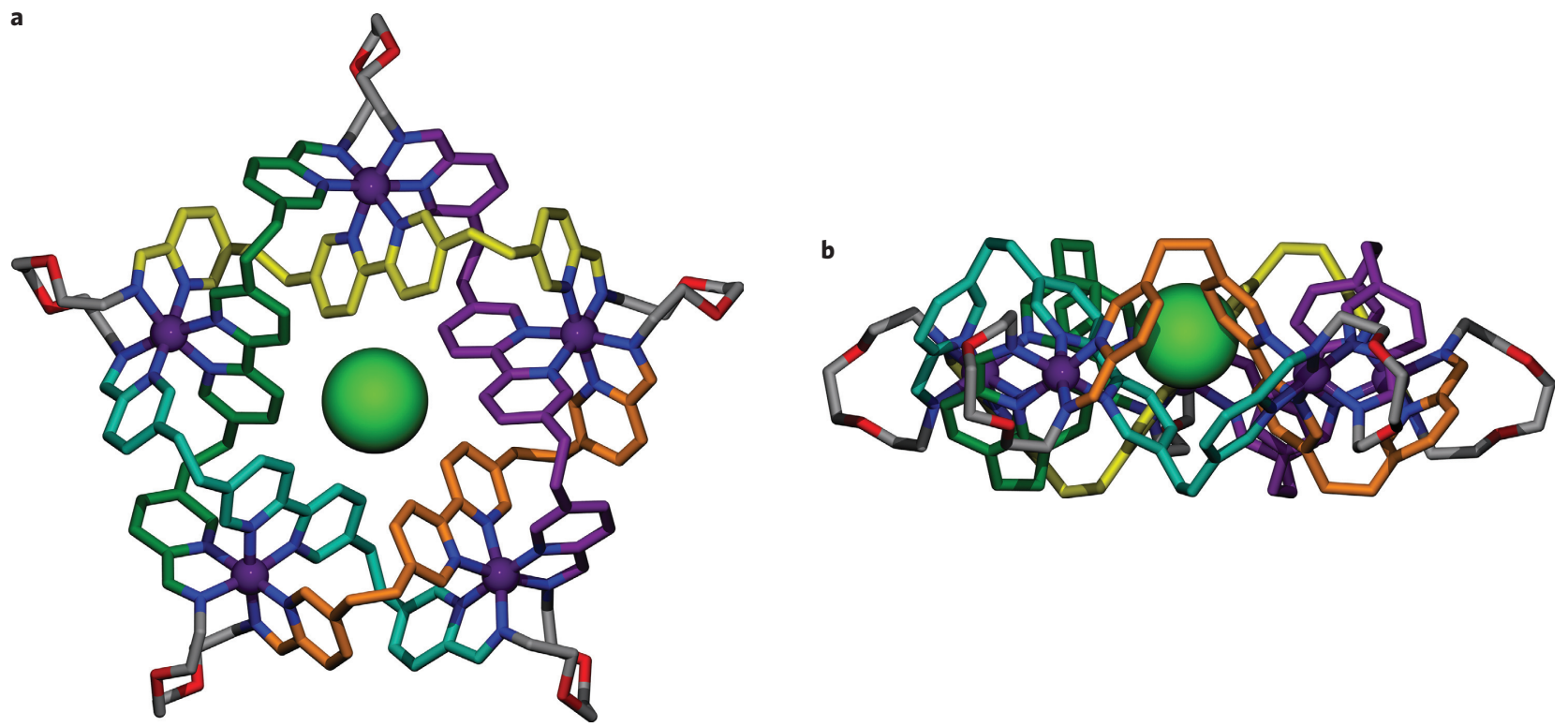

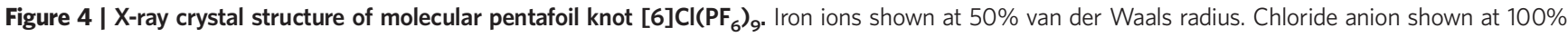
van der Waals radius. All other atoms shown in framework representation: nitrogen atoms, blue; oxygen atoms, red; carbon atoms originating from the diamine building block (5), grey; carbon atoms originating from the five dialdehyde building blocks (1), yellow, orange, dark green, purple and turquoise. $\mathrm{PF}_{6}{ }^{-}$anions, solvent molecules and hydrogen atoms are omitted for clarity. $\mathbf{a}$, View from above the plane of the five octahedral Fe( $\left.\|\right)$ ions, showing the symmetry and topology of the 160-atom-loop pentafoil knot with the chloride ion at the centre. $\mathrm{CH}^{\mathrm{a}}{ }^{\cdots} \mathrm{Cl}^{-}$distances $(\AA): 2.70,2.69,2.71,2.70,2.76,2.76$,

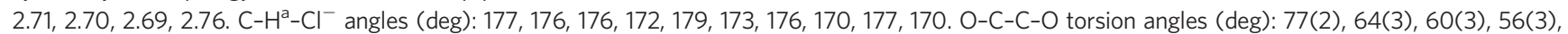
57(3). b, Side view showing the displacement of the chloride ion above the plane of the Fe(॥) ions and the interwoven double helix of the ligand. Crystallographic data and experimental details of the structural refinement for $[6] \mathrm{Cl}\left(\mathrm{PF}_{6}\right)_{9}$ are provided in the Supplementary Information. 
next, the bis-amine spacer must form a loop that allows its two amine groups to form imine bonds that coordinate to the same metal ion. Sequences of $-\mathrm{CH}_{2}-$ groups prefer antiperiplanar arrangements of carbon atoms (that is, $180^{\circ} \mathrm{C}-\mathrm{C}-\mathrm{C}-\mathrm{C}$ torsional angles), and forcing a chain to turn back on itself brings some of the $\mathrm{C}-\mathrm{H}$ groups into pseudo-1,3-diaxial steric clashes. In contrast, the lowest energy conformation of $-\mathrm{XCH}_{2} \mathrm{CH}_{2} \mathrm{O}-(\mathrm{X}=\mathrm{O}, \mathrm{N})$ units has the carbon-heteroatom bonds at $60^{\circ}$ to each other, a gauche conformation that is favoured for stereoelectronic reasons $s^{38}$, producing a low-energy turn. The lack of hydrogen atoms on the oxygen atoms also minimizes the steric interactions that occur as a consequence of the turn. Although the energetic cost of each of these effects may be individually small, multiplying them fivefold, as would be required to assemble a molecular pentafoil knot from alkyl chain diamines, is sufficient to tip the thermodynamic balance away from the cyclic-helicate knot to other oligomeric and polymeric products.

Treatment of $[6] \mathrm{Cl}\left(\mathrm{PF}_{6}\right)_{9}$ with a large excess (90 equiv.) of $\mathrm{AgPF}_{6}$ in $\mathrm{CD}_{3} \mathrm{CN}$ ( $298 \mathrm{~K}, 30 \mathrm{~min}$, Fig. 3) caused significant changes in parts of the ${ }^{1} \mathrm{H}$ NMR spectrum (Fig. 2e). The $\mathrm{H}^{\mathrm{a}}$ protons, heavily deshielded in $[6] \mathrm{Cl}\left(\mathrm{PF}_{6}\right)_{9}$ due to $\mathrm{CH} \cdots \mathrm{Cl}^{-}$hydrogen bonding (Fig. 2d), were shifted to $8.95 \mathrm{ppm}$ (Fig. 2e), indicating that the final chloride anion had been exchanged for hexafluorophosphate (confirmed by mass spectrometry), generating the empty cavity pentafoil knot $[6]\left(\mathrm{PF}_{6}\right)_{10}$ (Fig. 3). Treatment of $[6]\left(\mathrm{PF}_{6}\right)_{10}$ with $\mathrm{Bu}_{4} \mathrm{NCl}$ smoothly regenerates $[6] \mathrm{Cl}\left(\mathrm{PF}_{6}\right)_{9}$ (Fig. 3), but the ${ }^{1} \mathrm{H}$ NMR spectrum of the empty pentafoil knot shows no changes upon addition of other tetrabutylammonium salts (for example, $\mathrm{Bu}_{4} \mathrm{NBr}$, and $\left.\mathrm{Bu}_{4} \mathrm{NI}\right)$, demonstrating that $[6]\left(\mathrm{PF}_{6}\right)_{10}$ is a selective cavitand for the chloride ion.

\section{Conclusions}

The one-step synthesis of molecular pentafoil knot $[6] \mathrm{Cl}\left(\mathrm{PF}_{6}\right)_{9}$ assembles five metal cations, five bis-aldehyde and five bis-amine building blocks about one chloride anion, in $44 \%$ isolated yield. The number of different design features that are combined to assemble the knot is exceptional: the system uses octahedral metal-ion helicate formation to generate entwined ligand strands, short linkers between chelating groups to favour cyclic double helicates over linear triple helicates, anion template synthesis to select the correct number of crossing points, and reversible imine bond formation to join the complexes with the required strand-to-strand connectivity. Macrocyclization to form the covalent backbone of the pentafoil knot makes use of stereoelectronic effects to favour the required turns in the linking units and ligand-ligand interactions to promote mechanical bond formation over polymer formation. The symmetry of the cyclic helicate structures means that even individually rather weak interactions can significantly perturb the product distribution in the reaction mixture, in some cases usefully (for example, to form cyclic helicates of a particular handedness) and in others detrimentally (for example, to disfavour knot formation).

The pentafoil knot has symbolic significance in many ancient and modern cultures and religions (as does its two-dimensional projection, the pentagram) and features as the central emblem on the present-day flags of both Morocco and Ethiopia. The practical significance of its preparation in molecular form includes the lessons learned from the multitude of different structural design features ${ }^{10}$ used in its assembly and the potential for the synthesis of higher-order structures with precisely defined knotted architectures that may enable the role of entanglements in molecular materials to be elucidated and exploited.

\section{Methods}

Preparation of molecular pentafoil knot $[6] \mathrm{Cl}\left(\mathrm{PF}_{6}\right)_{9}$. A $d_{6}$-dimethylsulfoxide solution of anhydrous $\mathrm{FeCl}_{2}$ ( $250 \mu \mathrm{l}$ of a $210 \mathrm{mM}$ solution, $52 \mu \mathrm{mol}, 1.1$ equiv.) was added to dialdehyde 1 ( $20 \mathrm{mg}, 47 \mu \mathrm{mol}, 1$ equiv.) in $10 \mathrm{ml} d_{6}$-dimethylsulfoxide.
The resulting purple solution was sonicated in an ultrasonic bath for $10 \mathrm{~min}$ and heated at $60^{\circ} \mathrm{C}$ for $30 \mathrm{~min}$ to ensure complete dissolution of the dialdehyde. A $d_{6}$-dimethylsulfoxide solution of $2,2^{\prime}$-(ethylenedioxy)bis(ethylamine) $(1.00 \mathrm{ml}$ of a $52 \mathrm{mM}$ solution, $52 \mu \mathrm{mol}, 1.1$ equiv.) was added to the mixture. The resulting dark purple mixture was heated at $60{ }^{\circ} \mathrm{C}$ for 2 days. After cooling to room temperature, excess saturated aqueous $\mathrm{KPF}_{6}$ was added $(\sim 5 \mathrm{ml})$. A fine suspension of a purple material formed, which was collected on Celite, thoroughly washed with water, ethanol, dichloromethane and diethyl ether. The purple solid was dissolved in acetonitrile and concentrated under reduced pressure to give $[6] \mathrm{Cl}\left(\mathrm{PF}_{6}\right)_{9}$ as a purple powder (18 mg, $4.2 \mu \mathrm{mol}, 44 \%) .{ }^{1} \mathrm{H}$ NMR $\left(500 \mathrm{MHz}, \mathrm{CD}_{3} \mathrm{CN}\right) \delta 9.90(\mathrm{~d}, J=8.2 \mathrm{~Hz}$, $\left.10 \mathrm{H}, \mathrm{H}^{\mathrm{a}}\right), 9.04\left(\mathrm{~s}, 10 \mathrm{H}, \mathrm{H}^{\mathrm{i}}\right), 8.03\left(\mathrm{~d}, J=7.9 \mathrm{~Hz}, 10 \mathrm{H}, \mathrm{H}^{\mathrm{g}}\right), 7.86(\mathrm{~d}, J=7.7 \mathrm{~Hz}, 10 \mathrm{H}$ $\left.\mathrm{H}^{\mathrm{f}}\right), 7.50\left(\mathrm{~d}, J=7.9 \mathrm{~Hz}, 10 \mathrm{H}, \mathrm{H}^{\mathrm{b}}\right), 7.20\left(\mathrm{~s}, 10 \mathrm{H}, \mathrm{H}^{\mathrm{c}}\right), 6.43\left(\mathrm{~s}, 10 \mathrm{H}, \mathrm{H}^{\mathrm{h}}\right), 4.15-4.06$ $\left(\mathrm{m}, 10 \mathrm{H}, \mathrm{C}^{\mathrm{j}} \mathrm{H}_{\mathrm{A}}\right), 3.66\left(\mathrm{~d}, J=9.6 \mathrm{~Hz}, 20 \mathrm{H}, \mathrm{C}^{\mathrm{k}} \mathrm{H}_{\mathrm{A}}\right.$ and $\left.\mathrm{C}^{\mathrm{l}} \mathrm{H}_{\mathrm{A}}\right), 3.32(\mathrm{~d}, J=9.3 \mathrm{~Hz}, 10 \mathrm{H}$, $\left.\mathrm{C}^{\mathrm{l}} \mathrm{H}_{\mathrm{B}}\right), 3.23\left(\mathrm{~d}, J=13.9 \mathrm{~Hz}, \mathrm{C}^{\mathrm{j}} \mathrm{H}_{\mathrm{B}}\right), 3.19-3.15\left(\mathrm{~m}, 10 \mathrm{H}, \mathrm{C}^{\mathrm{d}} \mathrm{H}_{\mathrm{B}}\right), 3.15-3.07(\mathrm{~m}, 10 \mathrm{H}$, $\left.\mathrm{C}^{\mathrm{e}} \mathrm{H}_{\mathrm{A}}\right), 3.03-2.89\left(\mathrm{~m}, 20 \mathrm{H}, \mathrm{C}^{\mathrm{k}} \mathrm{H}_{\mathrm{B}}\right.$ and $\left.\mathrm{C}^{\mathrm{e}} \mathrm{H}_{\mathrm{B}}\right), 2.88-2.80\left(\mathrm{~m}, 10 \mathrm{H}, \mathrm{C}^{\mathrm{d}} \mathrm{H}_{\mathrm{A}}\right) .{ }^{13} \mathrm{C} \mathrm{NMR}$ $\left(126 \mathrm{MHz}, \mathrm{CD}_{3} \mathrm{CN}\right) \delta 174.0\left(\mathrm{C}^{\mathrm{i}}\right), 157.2\left(\mathrm{~N}-\mathrm{C}-\mathrm{C}^{\mathrm{a}}\right), 156.8\left(\mathrm{~N}-\mathrm{C}-\mathrm{C}^{\mathrm{g}}\right), 154.1\left(\mathrm{C}^{\mathrm{h}}\right)$,

$\left.\left.153.4\left(C^{\mathrm{c}}\right), 140.9\left(\mathrm{C}^{\mathrm{c}}-\underline{\mathrm{C}}-\mathrm{C}^{\mathrm{b}}\right) / \mathrm{C}^{\mathrm{f}}-\underline{\mathrm{C}}-\mathrm{C}^{\mathrm{h}}\right), 140.7\left(\mathrm{C}^{\mathrm{c}}-\mathrm{C}-\mathrm{C}^{\mathrm{b}}\right) / \mathrm{C}^{\mathrm{f}}-\underline{\mathrm{C}}-\mathrm{C}^{\mathrm{h}}\right), 140.3\left(\mathrm{C}^{\mathrm{e}}\right)$,

$138.9\left(C^{\mathrm{f}}\right), 129.5\left(\mathrm{C}^{\mathrm{g}}\right), 125.5\left(\mathrm{C}^{\mathrm{a}}\right), 71.4\left(\mathrm{C}^{\mathrm{l}}\right), 68.9\left(\mathrm{C}^{\mathrm{k}}\right), 61.4\left(\mathrm{C}^{\mathrm{j}}\right), 31.0\left(\mathrm{C}^{\mathrm{e}}\right), 30.2\left(\mathrm{C}^{\mathrm{d}}\right)$. High-resolution electrospray ionization mass spectrometry (HRESI-MS): $m / z=713.5736\left[\mathrm{M}-4\left(\mathrm{PF}_{6}\right)\right]^{5+}$ (calcd. for $\mathrm{C}_{160} \mathrm{H}_{170} \mathrm{ClF}_{24} \mathrm{Fe}_{5} \mathrm{~N}_{30} \mathrm{O}_{10} \mathrm{P}_{4}, 713.5750$ ). The proton and carbon assignments correspond to the lettering shown in Figs 1 and 3. Further details of the characterization can be found in the Supplementary Information.

The synthesis, characterization and spectroscopic information for all compounds, including those prepared in the synthetic route to building block $\mathbf{1}$, can be found in the Supplementary Information.

Received 15 September 2011; accepted 3 October 2011; published online 6 November 2011

\section{References}

1. Wasserman, S. A. \& Cozzarelli, N. R. Biochemical topology: applications to DNA recombination and replication. Science 232, 951-960 (1986).

2. Taylor, W. R. A deeply knotted protein structure and how it might fold. Nature 406, 916-919 (2000).

3. Taylor, W. R. \& Lin, K. Protein knots: a tangled problem. Nature 421, 25 (2003).

4. Wagner, J. R., Brunzelle, J. S., Forest, K. T. \& Vierstra, R. D. A light-sensing knot revealed by the structure of the chromophore-binding domain of phytochrome. Nature 438, 325-331 (2005).

5. Taylor, W. R. Protein knots and fold complexity: some new twists. Comput. Biol. Chem. 31, 151-162 (2007).

6. Saitta, A. M., Soper, P. D., Wasserman, E. \& Klein, M. L. Influence of a knot on the strength of a polymer strand. Nature 399, 46-48 (1999).

7. Arai, Y. et al. Tying a molecular knot with optical tweezers. Nature 399 , 446-448 (1999).

8. Menasco, W. W. \& Thistlethwaite, M. B. (eds) Handbook of Knot Theory (Elsevier, 2005)

9. Fenlon, E. E. Open problems in chemical topology. Eur. J. Org. Chem. 5023-5035 (2008).

10. Beves, J. E., Blight, B. A., Campbell, C. J., Leigh, D. A. \& McBurney, R. T. Strategies and tactics for the metal-directed synthesis of rotaxanes, knots, catenanes, and higher order links. Angew. Chem. Int. Ed. 50, 9260-9327 (2011).

11. Alexander, J. W. \& Briggs, G. B. On types of knotted curves. Ann. Math. 28, 562-586 (1926-1927).

12. Adams, C. C. The Knot Book (American Mathematical Society, 2004).

13. Dietrich-Buchecker, C. O. \& Sauvage, J-P. A synthetic molecular trefoil knot. Angew. Chem. Int. Ed. Engl. 28, 189-192 (1989).

14. Piguet, C., Bernardinelli, G. \& Hopfgartner, G. Helicates as versatile supramolecular complexes. Chem. Rev. 97, 2005-2062 (1997).

15. Ashton, P. R. et al. Molecular meccano 27. A template-directed synthesis of a molecular trefoil knot. Liebigs Ann. Recueil 2485-2494 (1997).

16. Rapenne, G., Dietrich-Buchecker, C. \& Sauvage, J-P. Copper(I)- or iron(II)templated synthesis of molecular knots containing two tetrahedral or octahedral coordination sites. J. Am. Chem. Soc. 121, 994-1001 (1999).

17. Safarowsky, O., Nieger, M., Fröhlich. R. \& Vögtle, F. A molecular knot with twelve amide groups-one-step synthesis, crystal structure, chirality. Angew. Chem. Int. Ed. 39, 1616-1618 (2000).

18. Lukin, O. \& Vögtle, F. Knotting and threading of molecules: chemistry and chirality of molecular knots and their assemblies. Angew. Chem. Int. Ed. 44, 1456-1477 (2005).

19. Feigel, M., Ladberg, R., Engels, S., Herbst-Irmer, R. \& Fröhlich, R. A trefoil knot made of amino acids and steroids. Angew. Chem. Int. Ed. 45, 5698-5702 (2006).

20. Fenlon, E. E. \& Ito, B. R. The thread \& cut method: syntheses of molecular knot precursors. Eur. J. Org. Chem. 3065-3068 (2008).

21. Guo, J., Mayers, P. C., Breault, G. A. \& Hunter, C. A. Synthesis of a molecular trefoil knot by folding and closing on an octahedral coordination template. Nature Chem. 2, 218-222 (2010).

22. Barran, P. E. et al. Active metal template synthesis of a molecular trefoil knot. Angew. Chem. Int. Ed. http://dx.doi.org/10.1002/anie.201105012 (2011). 
23. Carina, R. F., Dietrich-Buchecker, C. \& Sauvage, J-P. Molecular composite knots. J. Am. Chem. Soc. 118, 9110-9116 (1996).

24. Fujita, M., Ibukuro, F., Hagihara, H. \& Ogura, K. Quantitative self-assembly of a [2] catenane from two preformed molecular rings. Nature 367, 720-723 (1994).

25. Wang, L., Vysotsky, M. O., Bogdan, A., Bolte, M. \& Böhmer, V. Multiple catenanes derived from calix[4]arenes. Science 304, 1312-1314 (2004).

26. Lam, R. T. S. et al. Amplification of acetylcholine-binding catenanes from dynamic combinatorial libraries. Science 308, 667-669 (2005).

27. Ronson, T. K. et al. Stellated polyhedral assembly of a topologically complicated $\mathrm{Pd}_{4} \mathrm{~L}_{4}$ 'Solomon cube'. Nature Chem. 1, 212-216 (2009).

28. Hasell, T. et al. Triply interlocked covalent organic cages. Nature Chem. 2, 750-755 (2010)

29. Chichak, K. S. et al. Molecular Borromean rings. Science 304, 1308-1312 (2004).

30. Dietrich-Buchecker, C., Colasson, B., Jouvenot, D. \& Sauvage, J-P. Synthesis of multi-1,10-phenanthroline ligands with 1,3-phenylene linkers and their lithium complexes. Chem. Eur. J. 11, 4374-4386 (2005).

31. Hasenknopf, B., Lehn, J-M., Kneisel, B. O., Baum, G. \& Fenske, D. Self-assembly of a circular double helicate. Angew. Chem. Int. Ed. Engl. 35, 1838-1840 (1996).

32. Hasenknopf, B. et al. Self-assembly of tetra- and hexanuclear circular helicates. J. Am. Chem. Soc. 119, 10956-10962 (1997).

33. Hasenknopf, B., Lehn, J-M., Boumediene, N., Leize, E. \& Van Dorsselaer, A. Kinetic and thermodynamic control in self-assembly: sequential formation of linear and circular helicates. Angew. Chem. Int. Ed. 37, 3265-3268 (1998).

34. Leigh, D. A., Lusby, P. J., Teat, S. J., Wilson, A. J. \& Wong, J. K. Y. Benzylic imine catenates: readily accessible octahedral analogues of the Sauvage catenates. Angew. Chem. Int. Ed. 40, 1538-1543 (2001).

35. Hogg, L. et al. A simple general ligand system for assembling octahedral metal-rotaxane complexes. Angew. Chem. Int. Ed. 43, 1218-1221 (2004).

36. Hutin, M., Schalley, C. A., Bernardinelli, G. \& Nitschke, J. R. Helicate, macrocycle, or catenate: dynamic topological control over subcomponent selfassembly. Chem. Eur. J. 12, 4069-4076 (2006).

37. Price, J. R. et al. Copper(I)-templated synthesis of a $2,2^{\prime}$-bipyridine derived [2] catenane: synthetic, modelling, and X-ray studies. Aust. J. Chem. 62, 1014-1019 (2009).
38. Murcko, M. A. \& DiPaola, R. A. Ab initio molecular orbital conformational analysis of prototypical organic systems. 1. Ethylene glycol and 1,2-dimethoxyethane. J. Am. Chem. Soc. 114, 10010-10018 (1992).

39. Ohsawa, Y., DeArmond, M. K., Hanck, K. W. \& Moreland, C. G. A proton NMR study of reduced paramagnetic tris $\left(2,2^{\prime}\right.$-bipyridine) complexes of iron(II), ruthenium(II) and osmium(II). J. Am. Chem. Soc. 107, 5383-5386 (1985).

40. Mamula, O., von Zelewsky, A. \& Bernardinelli, G. Completely stereospecific self-assembly of a circular helicate. Angew. Chem. Int. Ed. 37, 290-293 (1998).

41. Krämer, R., Lehn, J-M. \& Marquis-Rigault, A. Self-recognition in helicate self-assembly: spontaneous formation of helical metal complexes from mixtures of ligands and metal ions. Proc. Natl Acad. Sci. USA 90, 5394-5398 (1993).

42. Albrecht, M. 'Let's twist again'-double-stranded, triple-stranded, and circular helicates. Chem. Rev. 101, 3457-3497 (2001).

43. Nitschke, J. R. Construction, substitution, and sorting of metallo-organic structures via subcomponent self-assembly. Acc. Chem. Res. 40, 103-112 (2007).

\section{Acknowledgements}

The authors thank the Diamond Light Source (UK) for synchrotron beamtime on I19 (XR029), the Engineering and Physical Sciences Research Council (EPSRC) National Crystallography Service for data collection, and the EPSRC National Mass Spectrometry Service Centre (Swansea, UK) and C.L. Mackay (SIRCAMS, University of Edinburgh) for high-resolution mass spectrometry. J.E.B. and D.S. are Swiss National Science Foundation postdoctoral fellows. This research was funded by the EPSRC and the Academy of Finland (K.R., projects 212588 and 218325).

\section{Author contributions}

J-F.A., J.E.B., R.T.M. and D.S. carried out the synthesis and characterization studies, helped plan the experiments, and participated in the preparation of the manuscript. K.R. solved the crystal structure. D.A.L. helped plan the experiments and prepare the manuscript.

\section{Additional information}

The authors declare no competing financial interests. Supplementary information and chemical compound information accompany this paper at www.nature.com/ naturechemistry. Reprints and permission information is available online at http://www. nature.com/reprints. Correspondence and requests for materials should be addressed to D.A.L. 